\title{
Steric Effect on Dimer Radical Cation Formation of Poly(3,6-di-tert-butyl-9-vinylcarbazole) and Its Dimeric Model Compounds Studied by Laser Photolysis
}

\author{
Yoshinobu TsujII, Kazukiyo TaKami, Akira Tsuchida, \\ Shinzaburo ITo, Yoshihiko ONOGI, \\ and Masahide Yамамото* \\ Department of Polymer Chemistry, Faculty of Engineering, Kyoto University, \\ Yoshida, Sakyo-ku, Kyoto 606, Japan
}

(Received September 18, 1989)

\begin{abstract}
The steric effect of bulky tert-butyl group on the formation of a dimer radical cation was investigated. Transient absorption spectra for poly(3,6-di-tert-butyl-9-vinylcarbazole) (PBVCz) and its dimeric model compounds were measured by laser photolysis. Though the interaction was weak compared with the case of carbazole chromophores, all these compounds formed the dimer radical cation and gave the dimer band in a visible region and the charge-resonance (CR) band around $c a .2000 \mathrm{~nm}$. This is quite in contrast to the result that the meso isomer of 2,4-bis(3,6-di-tert-butyl-9-carbazolyl)pentane and 1,3-bis(3,6-di-tert-butyl-9-carbazolyl)propane do not form an intramolecular excimer. In these compounds, two chromophores cannot come close together and the dimer radical cation has a rather loose conformation. This means that the conformational requirement for the formation of the dimer radical cation is rather loose and that the stabilization energy is larger than that of the excimer. In PBVCz, interactions among more than two chromophores are hindered and the partially-overlapped dimer radical cation is formed in contrast to the case of poly $(N$-vinylcarbazole $)$.

KEY WORDS Steric Hindrance / Neighboring Chromophore Interaction / Dimer Radical Cation / Laser Photolysis / Charge-Resonance Band / Poly(3,6-di-tert-butyl-9-vinylcarbazole) /
\end{abstract}

Numerous investigations have been made on the photophysical and photochemical properties of polymers having pendant aromatic chromophores. ${ }^{1-5}$ An important characteristic of such polymers is that the local concentration is very high even in a dilute solution. Therefore, an excited state of a chromophore is expected to be stabilized to form an excimer by interaction with the neighboring chromophore. One of such polymers, poly( $N$-vinylcarbazole $)$ (PVCz) is known to form at least two kinds of excimers, the sandwich excimer with a fully-overlapped conformation and the second excimer with a partially-overlapped conformation. ${ }^{6-14}$ These excimers were identified by comparison with dimeric model compounds: meso- and rac-di( $N$-carbazolyl)pentanes ( $\mathrm{m}$ - and $\mathrm{r}-\mathrm{CzPe}$ ) form the sandwich excimer and the second excimer, respectively. ${ }^{13,15}$

Radical cations of aromatic chromophores are also stabilized by interactions with neighboring chromophore. The stabilization of the radical cation leads to the formation of a dimer radical cation, which has been investigated in intramolecular ${ }^{16-21}$ and inter-

\footnotetext{
* To whom correspondence should be addressed.
} 
molecular systems. ${ }^{22-27}$ Concerning the dimer radical cation of a carbazole $(\mathrm{Cz})$ chromophore, two kinds of dimer radical cations have been reported for $\mathrm{m}$ - and $\mathrm{r}-\mathrm{CzPe},{ }^{18}$ where the overlapping of two $\mathrm{Cz}$ chromophores is different. That is, the meso isomer forms the sandwich dimer radical cation with the same fully-overlapped conformation as the sandwich excimer, and the racemic isomer forms the second dimer radical cation with the same partially-overlapped conformation as the second excimer. In the previous paper, ${ }^{19}$ we investigated the stability of these dimer radical cations and the $\mathrm{Cz}$ radical cation $\left(\mathrm{Cz}^{+}\right)$formed in $\mathrm{PVCz}$ by the radical ion transfer method, ${ }^{28}$ and concluded that the sandwich dimer radical cation is more stabilized than the second one and that $\mathrm{Cz}^{+}$formed in $\mathrm{PVCz}$ is the most stable. ${ }^{29}$ This was supported by measurement of the charge-resonance (CR) band whose absorption was observed in a near-infrared wavelength region. ${ }^{20}$ The sandwich and the second dimer radical cations showed the CR band around $1600 \mathrm{~nm}$ and $1800 \mathrm{~nm}$, respectively. The CR band reflects the strength of the neighboring interaction in the dimer radical cation; the CR band is shifted to shorter wavelengths with the increasing interaction with the neighboring chromophore.

The fluorescent behavior of poly(3,6-di-tert-

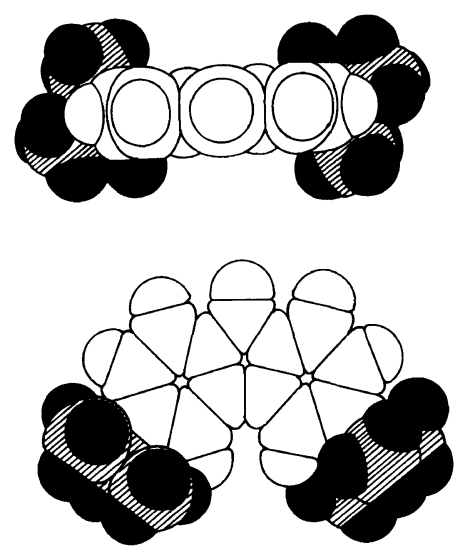

Figure 1. Molecular structure of 3,6-di-tert-butylcarbazole. Shaded parts show tert-butyl groups. butyl-9-vinylcarbazole) (PBVCz) and its dimeric model compounds, 2,4-bis(3,6-di-tert-butyl9-carbazolyl)pentanes ( $\mathrm{BCzPe})$ was studied at our laboratory. ${ }^{30}$ Figure 1 shows the molecular structure of 3,6-di-tert-butylcarbazole. tertButyl groups are very bulky as shown in the shaded parts, and their steric hindrance is considered to be very large. Consequently, the neighboring interaction in the excited state is suppressed by the steric hindrance of bulky tert-butyl groups introduced in the $\mathrm{Cz}$ chromophore. $\mathrm{PBVCz}$ gives only one kind of unstable excimer whose stability is smaller than the second excimer. The meso isomer of $\mathrm{BCzPe}$ forms no excimer at all owing to the steric hindrance and in the case of the racemic isomer of $\mathrm{BCzPe}$, the fraction of the excimer is very small compared with that of $\mathrm{r}-\mathrm{CzPe}$.

In the present study, we carried out transient absorption measurements of radical cations of these compounds having bulky tert-butyl groups in $\mathrm{Cz}$ chromophore, and investigated the effect of steric hindrance on the radical cation interaction.

\section{EXPERIMENTAL}

\section{Materials}

The preparation of poly(3,6-di-tert-butyl-9vinylcarbazole) (PBVCz), 2,4-bis(3,6-di-tertbutyl-9-carbazolyl)pentane (BCzPe), and 3,6di-tert-butyl-9-ethylcarbazole $(\mathrm{BEtCz})$ was described in detail previously. ${ }^{30} \mathrm{PBVCz}$ with a molecular weight of $c a .1 \times 10^{6}$ was obtained by a cationic polymerization of its vinyl monomer, 3,6-di-tert-butyl-9-vinylcarbazole. As for $\mathrm{BCzPe}$, the racemic and the meso isomers ( $\mathrm{r}-$ and $\mathrm{m}-\mathrm{BCzPe}$ ) were separated by liquid chromatography and were used as models for syndiotactic and isotactic dyads in PBVCz, respectively. 1,3-Bis(3,6-di-tert-butyl9-carbazolyl)propane (BCzPr) was synthesized from 3,6-di-tert-butylcarbazolylsodium and 1,3-dibromopropane (Wako Pure Chem. Ind., Ltd.) and was purified by silica-gel column chromatography and recrystallization. 
An electron acceptor, dimethyl terephthalate (DMTP, Wako Pure Chem. Ind., Ltd.) was purified several times by recrystallization.

Acetonitrile (MeCN, Wako Pure Chem. Ind., Ltd.) was distilled over $\mathrm{P}_{2} \mathrm{O}_{5}$ several times. Tetrahydrofuran (THF, Dotite Spectrosol) was used without further purification.

\section{Measurements}

Transient absorption measurements were made by nanosecond laser photolysis. A 351-nm laser pulse of XeF excimer laser (Lambda Physik EMG101 MSC) was used for excitation. The laser pulse had a pulse energy of $c a .60 \mathrm{~mJ}$ and a fwhm of $c a .17 \mathrm{~ns}$. Two kinds of detection systems were used; one equipped with a photomultiplier tube (Hamamatsu, R928) as a detector ${ }^{20,21,28}$ and the other equipped with a photovoltaic indium arsenide (InAs) diode (Hamamatsu, P838). ${ }^{20,31}$ The former photomultiplier-system is well suited for measurement in the visible region $(350$ $850 \mathrm{~nm}$ ) and its rise time is $c a .5 \mathrm{~ns}$. The latter photodiode-system was used for measurement in the visible and the near-infrared regions $(350-2200 \mathrm{~nm})$ and has a response time of $c a$. $500 \mathrm{~ns}$.

An electron donating chromophore, 3,6-ditert-butylcarbazole $(\mathrm{BCz})$, was excited selectively by the laser pulse in the presence of an electron acceptor, DMTP $(0.05 \mathrm{M})$, and the transient absorption decays and spectra of radical ions formed by a photoinduced electron transfer reaction were measured. The pulse intensity was attenuated properly by filters. The concentration of $\mathrm{BCz}$ chromophore was adjusted to about unity in the absorbance at $351 \mathrm{~nm}$. THF solvent was used for $\mathrm{PBVCz}$ system. The other systems were measured in $\mathrm{MeCN}$. All samples were degassed by the freeze-pump-thaw method in a 1-cm quartz cell.

\section{RESULTS}

Figure 2 shows the transient absorption

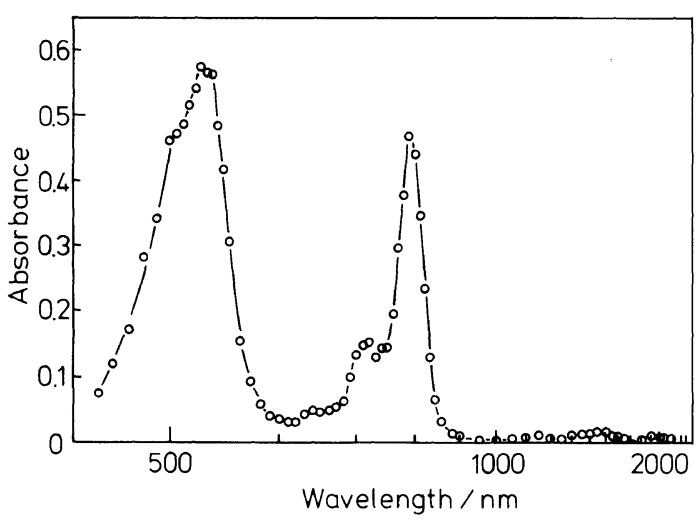

Figure 2. Transient absorption spectrum of $\mathrm{BEtCz}-$ DMTP $(0.05 \mathrm{M})$ system in $\mathrm{MeCN}$ at $25^{\circ} \mathrm{C}$ at $1 \mu \mathrm{s}$ after excitation. The absorbance of $\mathrm{BEtCz}$ at $351 \mathrm{~nm}$ is about unity.

spectrum of the $\mathrm{BEtCz}-\mathrm{DMTP}$ system in $\mathrm{MeCN}$ at $25^{\circ} \mathrm{C}$ at $1 \mu \mathrm{s}$ after excitation. The absorption band of a radical cation of $\mathrm{BEtCz}$ (BEtCz $z^{+}$) appears at $c a .795 \mathrm{~nm}$ along with that of a radical anion of DMTP (DMTP -) observed at $c a .530 \mathrm{~nm} .^{28,32}$ No absorption was observed in the near-infrared region $(1000$ $2000 \mathrm{~nm})$. The monomer band of $\mathrm{BEtCZ}^{+}$is similar in shape and peak wavelength to that of the radical cation of 9-ethylcarbazole $\left(\mathrm{EtCz}^{+}\right) .{ }^{19,28}$ Therefore, the tert-butyl group is considered to have little effect on a radical cationic state of $\mathrm{Cz}$ chromophore.

Figure 3 shows the transient absorption spectra of the dimeric model compoundDMTP systems in $\mathrm{MeCN}$ at $25^{\circ} \mathrm{C}$ at $1 \mu$ s after excitation. Each system gives two absorption bands of the radical cation of $\mathrm{BCz}$ chromophore; one is the visible dimer band and the other is the band around $c a .2000 \mathrm{~nm}$. The former band shifts to shorter wavelengths and is broader than that of $\mathrm{BEtCz}^{+}$; the peak wavelength is at $760 \mathrm{~nm}$ for $\mathrm{m}-\mathrm{BCzPe}$ (Figure $3 \mathrm{~A}$ ), at $750 \mathrm{~nm}$ for $\mathrm{BCzPr}$ (Figure 3B), and at $700 \mathrm{~nm}$ for $\mathrm{r}-\mathrm{BCzPe}$ (Figure $3 \mathrm{C}$ ). The latter is the $\mathrm{CR}$ band of the dimer radical cation formed intramolecularly. The CR band shifts to the shorter wavelengths in the order: $>2100 \mathrm{~nm}$ for $\mathrm{m}-\mathrm{BCzPe}$ (Figure 3A), $2100 \mathrm{~nm}$ for $\mathrm{BCzPr}$ 


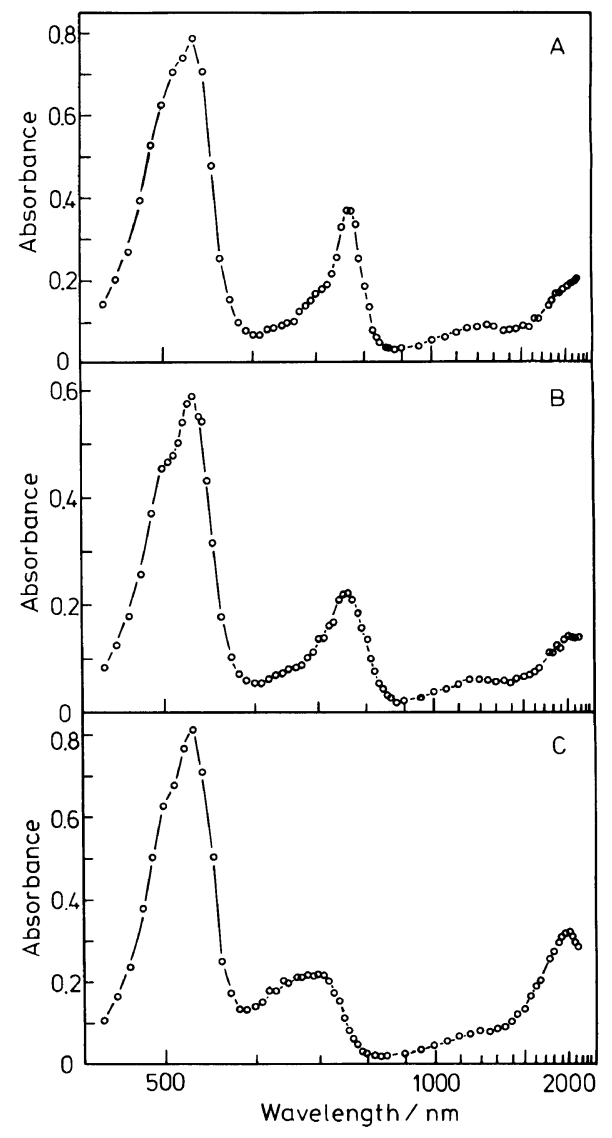

Figure 3. Transient absorption spectra of the dimeric model compound-DMTP $(0.05 \mathrm{M})$ systems in $\mathrm{MeCN}$ at $25^{\circ} \mathrm{C}$ at $1 \mu \mathrm{s}$ after excitation. A, m-BCzPe; B, BCzPr; C, $\mathrm{r}-\mathrm{BCzPe}$. The absorbance of $\mathrm{BCz}$ chromophore at $351 \mathrm{~nm}$ is about unity.

(Figure 3B), and $2000 \mathrm{~nm}$ for $\mathrm{r}-\mathrm{BCzPe}$ (Figure 3C). For all dimeric model compounds, there was no obvious absorption peak of the monomer radical cation ( $c a .795 \mathrm{~nm}$ ), though the molar extinction coefficient $(\varepsilon)$ of the monomer radical cation is larger than that of the dimer radical cation as described later. This suggests that the contribution of the monomer radical cation can be neglected. The molar extinction coefficient $(\varepsilon)$ of dimer radical cation was estimated on the basis of that of DMTPat $530 \mathrm{~nm}(\varepsilon=12300)^{28}$ by assuming that the concentration of the dimer radical cation is equal to that of $\mathrm{DMTP}^{-}$, since almost all the
Table I. Peak wavelength $\left(\lambda_{\max }\right)$ and molar extinction coefficient $(\varepsilon)$ of the visible dimer band and those of the CR band for dimeric model compounds

\begin{tabular}{lcrcc}
\hline & $\lambda_{\max } / \mathrm{nm}$ & $\varepsilon$ & $\lambda_{\text {max }} / \mathrm{nm}$ & $\varepsilon$ \\
\hline $\mathrm{BEtCz}^{\mathrm{a}}$ & 795 & 10500 & - & - \\
$\mathrm{m}-\mathrm{BCzPe}$ & 760 & 6400 & $>2100$ & 3700 \\
$\mathrm{BCzPr}$ & 750 & 4600 & 2100 & 3000 \\
$\mathrm{r}-\mathrm{BCzPe}$ & 700 & 3900 & 2000 & 5400 \\
\hline
\end{tabular}

a The values for $\mathrm{BEtCz}$ are for the monomer radical cation.

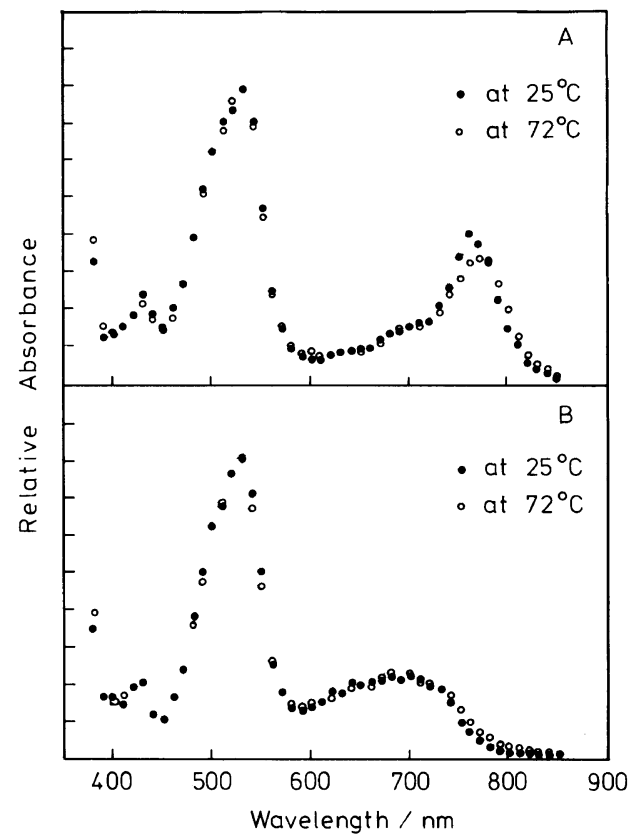

Figure 4. Temperature dependence of the visible dimer band of BCzPe-DMTP $(0.05 \mathrm{M})$ systems in $\mathrm{MeCN}$ at $1 \mu \mathrm{s}$ after excitation. A, m-BCzPe; B, r-BCzPe. Closed and open circles indicate the spectra measured at $25^{\circ} \mathrm{C}$ and $72^{\circ} \mathrm{C}$, respectively, and these spectra are normalized by the absorbance of DMTP- at $530 \mathrm{~nm}$.

radical cations form the dimer radical cation. Table I gives the peak wavelength $\left(\lambda_{\max }\right)$ and the molar extinction coefficient $(\varepsilon)$ of the visible dimer band, and those of the CR band.

The transient absorption spectra of the visible dimer band were measured at $25^{\circ} \mathrm{C}$ and $72^{\circ} \mathrm{C}$ to observe the dissociation of the dimer 


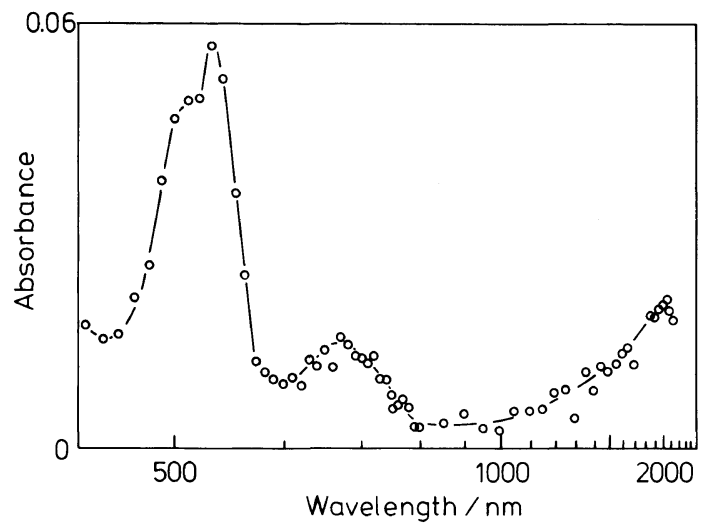

Figure 5. Transient absorption spectrum of $\mathrm{PBVCz}$ DMTP $(0.05 \mathrm{M})$ system in THF at $25^{\circ} \mathrm{C}$ at $1 \mu$ s after excitation. The absorbance of $\mathrm{BCz}$ chromophore is about unity.

radical cation to the monomer radical cation. These spectra were normalized by the absorbance of DMTP- at $530 \mathrm{~nm}$. Figure $4 \mathrm{~A}$ and B are for $\mathrm{m}-\mathrm{BCzPe}$ and $\mathrm{r}-\mathrm{BCzPe}$, respectively. The visible dimer band did not change obviously with increase in temperature in any system, though the visible dimer band for $\mathrm{m}-\mathrm{BCzPe}$ showed a little longer-wavelength shift at $72^{\circ} \mathrm{C}$. In this way, the dimer radical cation could scarcely dissociate into the monomer radical cation at $72^{\circ} \mathrm{C}$.

Figure 5 shows the transient absorption spectrum of the PBVCz-DMTP system in THF at $25^{\circ} \mathrm{C}$ at $1 \mu \mathrm{s}$ after excitation. The radical cation formed in $\mathrm{PBVCz}$ was found to have two absorption bands; one is a very broad band around $700 \mathrm{~nm}$ and the other is the CR band around $2000 \mathrm{~nm}$. This spectrum is similar to that of the r-BCzPe-DMTP system. The absorbance of the spectrum was very small compared with that of the monomeric and dimeric model compounds. This is partly due to the low quantum efficiency of ionization in low dielectric constant of THF and partly due to $\mathrm{S}-\mathrm{S}$ annihilation along the polymer chain.

\section{DISCUSSION}

Figure 6 shows the energy level diagram of

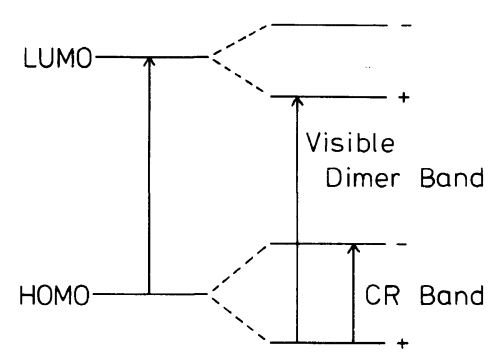

Figure 6. Schematic diagram of the CR band of dimer radical cation.

the dimer radical cation. The highest occupied molecular orbital (HOMO) and lowest unoccupied molecular orbital (LUMO) of a chromophore are split into two levels by the interaction with the neighboring chromophore. The CR band corresponds to the transition between two levels of split HOMO. With increasing interaction, the width of the splitting increases and the CR band shifts to shorter wavelengths. As for the dimeric model compounds having $\mathrm{Cz}$ chromophores without tert-butyl groups, the sandwich and second dimer radical cations give the $C R$ band around $1600 \mathrm{~nm}$ and $1800 \mathrm{~nm}$, respectively. ${ }^{20}$ The CR bands of the dimer radical cations of $\mathrm{BCz}$ chromophore $(c a .2000 \mathrm{~nm})$ shift to longer wavelengths than those of the $\mathrm{Cz}$ chromophore. This means that the interaction in the dimer radical cation is weakened by steric hindrance of tert-butyl groups. That is, the stabilization energy is less than $2 \mathrm{kcal} \mathrm{mol}^{-1}$, which we estimated for the second dimer radical cation of $\mathrm{r}-\mathrm{CzPe}{ }^{19}$

However, the monomer radical cation was not detected and dissociation of the dimer radical cation to the monomer radical cation was not observed at $72^{\circ} \mathrm{C}$ (Figure 4). This suggests that the stabilization energy of the dimer radical cation is sufficiently large compared with the thermal energy.

The neighboring interaction in the dimer radical cation is very different from that in the excimer, especially in $\mathrm{m}-\mathrm{BCzPe}$ and $\mathrm{BCzPr}$. In contrast to the fact that $\mathrm{m}-\mathrm{BCzPe}$ and $\mathrm{BCzPr}$ 
do not form the excimer, ${ }^{30}$ they form the dimer radical cation easily. In $\mathrm{m}-\mathrm{BCzPe}$ and $\mathrm{BCzPr}$, two $\mathrm{BCz}$ chromophores cannot come close together due to steric hindrance of tert-butyl groups and the dimer radical cation has a loose conformation. This means that the conformational requirement for the formation of the dimer radical cation is loose as compared with that of the excimer, and that the stabilization energy of the dimer radical cation is larger than that of the excimer.

The shift of the CR bands suggests that interaction increases in the order: $\mathrm{m}-\mathrm{BCzPe}^{+}<$ $\mathrm{BCzPr}^{+}<\mathrm{r}-\mathrm{BCzPe}^{+}$. This increase is accompanied by shorter-wavelength shift and broadening (the decreasing $\varepsilon$ ) of the visible dimer band and by increasing $\varepsilon$ of the CR band. The differences in interactions among the dimeric model compounds are due to configurational differences. In the racemic isomer of the pentane model, TT conformation is stable, having interaction between two chromophores. Then, $\mathrm{r}-\mathrm{BCzPe}$ forms the dimer radical cation in the partially-overlapped conformation near the TT one. This is the most stable among the three dimeric model compounds. On the other hand, $\mathrm{m}-\mathrm{BCzPe}$ cannot form the dimer radical cation in TT conformation (fully-overlapped conformation) owing to steric hindrance of the tert-butyl groups in $\mathrm{BCz}$ chromophore. This means that $\mathrm{m}-\mathrm{BCzPe}$ also forms the partiallyoverlapped dimer radical cation. To form the partially-overlapped dimer radical cation, m$\mathrm{BCzPe}$ must take the distorted conformation and the dimer radical cation is unstable as compared with that of $\mathrm{r}-\mathrm{BCzPe}$. Thus, all dimeric model compounds form the dimer radical cation with the partially-overlapped conformation and the stability of the dimer radical cation is affected by slight change in the dimer structure induced by configurational differences.

As for the radical cation formed in $\mathrm{PBVCz}$, the transient absorption spectrum is similar to that of $\mathrm{r}-\mathrm{BCzPe}+$. This suggests that $\mathrm{PBVCz}$ forms the partially-overlapped dimer radical cation in the syndiotactic dyad, which corresponds to the racemic isomer of the pentane model. The situation is very different from the case of $\mathrm{PVCz}$. The radical cation formed in $\mathrm{PVCz}$ is considered to interact with more than two neighboring chromophores and to be more stabilized than the dimer radical cation. ${ }^{19}$ By introduction of tert-butyl groups to the $\mathrm{BCz}$ chromophore, interactions of more than two chromophores are hindered and the dimer radical cation is formed in a polymer chain.

\section{CONCLUSION}

Dimeric model compounds having $\mathrm{BCz}$ chromophores form the dimer radical cation in spite of the steric hindrance of tert-butyl groups, though the interaction is weakened compared with the dimer radical cation of $\mathrm{Cz}$ chromophore. The neighboring chromophore interaction is increased in the order: $\mathrm{m}$ $\mathrm{BCzPe}^{+}<\mathrm{BCzPr}^{+}<\mathrm{r}-\mathrm{BCzPe}^{+}$. The difference in the stability of the dimer radical cation is due to the little change in the dimer structure induced by the configurational difference. It is noteworthy that formation of the dimer radical cation was observed even in $\mathrm{m}-\mathrm{BCzPe}$ and $\mathrm{BCzPr}$ which cannot form excimers. This suggests that the conformational requirement for the formation of the dimer radical cation is loose as compared with that of the excimer, and that the stabilization energy of the dimer radical cation is larger than that of the excimer. As for PBVCz, interactions among more than two chromophores are hindered by steric hindrance in contrast to the case of $\mathrm{PVCz}$ and the formation of the same partially-overlapped dimer radical cation as $\mathrm{r}-\mathrm{BCzPe}$ was observed.

\section{REFERENCES}

1. J. Guillet, "Polymer Photophysics and Photochemistry," Cambridge University Press, London, 1985. 
2. M. Winnik, "Photophysical and Photochemical Tools in Polymer Science," D. Reidel Publishing Co., Dordrecht, 1986.

3. V. Balzani Ed., "Supramolecular Photochemistry," D. Reidel Publishing Co., Dordrecht, 1987.

4. D. Phillips and G. Rumbles, "Photochemistry and Photophysics in Polymers," N. S. Allen and W. Schnabel, Eds., Elsevier Applied Science Publishers, London, 1984, p 153.

5. A. J. Roberts and I. Soutar, "Polymer Photophysics, "D. Phillips, Ed., Chapman and Hall, London, 1985, Chapter 5; E. Chiellini, ibid., Chapter 8 .

6. W. Klöpffer, Chem. Phys. Lett., 4, 193 (1969); W. Klöpffer, J. Chem. Phys., 50, 2337 (1969).

7. G. E. Johnson, J. Chem. Phys., 62, 4697 (1975).

8. M. Yokoyama, T. Tamamura, M. Atsumi, M. Yoshimura, Y. Shirota, and H. Mikawa, Macromolecules, 8, 101 (1975).

9. A. Itaya, K. Okamoto, and S. Kusabayashi, Bull. Chem. Soc. Jpn., 49, 2082 (1976).

10. K. P. Ghiggino, R. D. Wright, and D. Phillips, Eur. Polym. J., 14, 567 (1978); K. P. Ghiggino, D. A. Archibald, and P. J. Thistlethwaite, J. Polym. Sci., Polym. Lett. Ed., 18, 673 (1980).

11. D. $\mathrm{Ng}$ and J. E. Guillet, Macromolecules, 14, 405 (1981).

12. H. Masuhara, N. Tamai, N. Mataga, F. C. De Schryver, J. Vandendriessche, and N. Boens, Chem. Phys. Lett., 95, 471 (1983).

13. F. Evers, K. Kobs, R. Memming, and D. R. Terrell, J. Am. Chem. Soc., 105, 5988 (1983).

14. H. F. Kauffmann, W. Weixelbaumer, J. Buerbaumer, A. Schmoltner, and O. F. Olaj, Macromolecules, 18, 104 (1985).

15. F. C. De Schryver, J. Vandendriessche, S. Toppet, K. Demeyer, and N. Boens, Macromolecules, 15, 406 (1982); J. Vandendriessche, P. Palmans, S. Toppet, N. Boens, F. C. De Schryver, and H. Masuhara, J. Am. Chem. Soc., 106, 8057 (1984); F. C. De Schryver, P. Collart, J. Vandendriessche, R. Goedeweeck, A. M. Swinnen, and M. Van der Auweraer, Acc. Chem. Res., 20, 159 (1987).

16. H. Yoshimi and K. Kuwata, Mol. Phys., 23, 297 (1972).
17. S. Irie, H. Horii, and M. Irie, Macromolecules, 13, 1355 (1980); S. Irie and M. Irie, ibid., 19, 2182 (1986).

18. H. Masuhara, N. Tamai, N. Mataga, F. C. De Schryver, and J. Vandendriessche, J. Am. Chem. Soc., 105, 7256 (1983); H. Masuhara, K. Yamamoto, N. Tamai, K. Inoue, and N. Mataga, J. Phys. Chem., 88, 3971 (1984).

19. Y. Tsujii, A. Tsuchida, M. Yamamoto, and Y. Nishijima, Macromolecules, 21, 665 (1988).

20. M. Yamamoto, Y. Tsujii, and A. Tsuchida, Chem. Phys. Lett., 154, 559 (1989).

21. A. Tsuchida, Y. Tsujii, S. Ito, M. Yamamoto, and Y. Wada, J. Phys. Chem., 93, 1244 (1989).

22. I. C. Lewis and L. S. Singer, J. Chem. Phys., 43, 2712 (1965).

23. T. C. Chiang and A. H. Reddoch, J. Chem. Phys., 52, 1371 (1970).

24. R. E. Bühler and W. Funk, J. Phys. Chem., 79, 2098 (1975).

25. B. Badger, B. Brocklehurst, and R. D. Russell, Chem. Phys. Lett., 1, 122 (1967); B. Badger and B. Brocklehurst, Trans. Faraday Soc., 65, 2576 (1969); B. Badger and B. Brocklehurst, ibid., 65, 2582 (1969); B. Badger and B. Brocklehurst, ibid., 65, 2588 (1969).

26. A. Kira, S. Arai, and M. Imamura, J. Chem. Phys., 54, 4890 (1971); A. Kira, S. Arai, and M. Imamura, J. Phys. Chem., 76, 1119 (1972); A. Kira and M. Imamura, ibid., 83, 2267 (1979).

27. J. R. Grover, E. A. Walters, and E. T. Hui, J. Phys. Chem., 91, 3233 (1987).

28. A. Tsuchida, M. Yamamoto, and Y. Nishijima, $J$. Phys. Chem., 88, 5062 (1984).

29. M. Washio, S. Tagawa, and Y. Tabata, Polym. J., 13, 935 (1981).

30. S. Ito, K. Takami, and M. Yamamoto, Makromol. Chem., Rapid Commun., 10, 79 (1989); S. Ito, K. Takami, Y. Tsujii, and M. Yamamoto, Macromolecules, in press.

31. L. M. Dorfman, "Investigation of Rates and Mechanisms of Reactions," G. G. Hammes, Ed., Wiley-Interscience, New York, 1974, Chapter 11.

32. U. Lachish, R. W. Anderson, and D. J. Williams, Macromolecules, 13, 1143 (1980). 